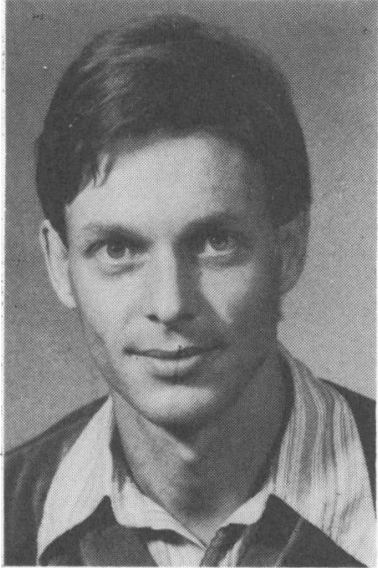

K. Niemelä

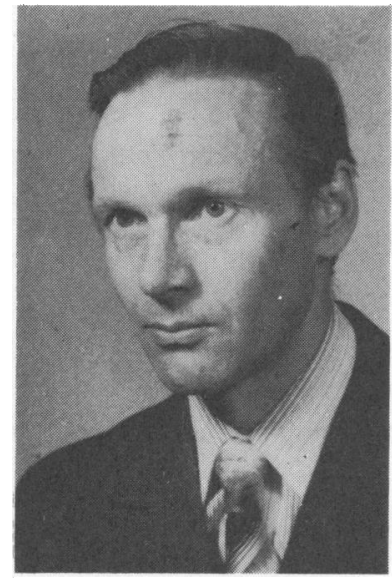

I. Palatsi

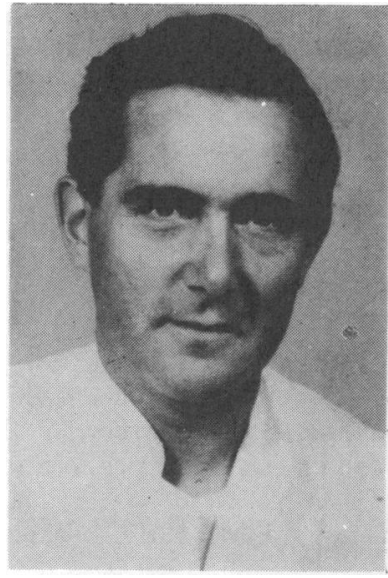

J. Takkunen

\title{
THE OXYGEN UPTAKE - WORK-OUTPUT RELATIONSHIP OF RUNNERS DURING GRADED CYCLING EXERCISE: SPRINTERS VS. ENDURANCE RUNNERS
}

\author{
K. NIEMELÄ, MD, I. PALATSI, MD, and J. TAKKUNEN, MD \\ Division of Cardiology, Department of Medicine, University Central Hospital, SF-90220 Oulu 22, Finland
}

Correspondence to:

Dr. K. Niemelä

\begin{abstract}
In order to study oxygen consumption $\left(\dot{\mathrm{V}}_{2}\right)$ for a given work load at the exhaustive level of a graded cycling exercise in well-trained runners, a progressive cycle ergometer exercise test was performed on 9 sprinters and 12 endurance runners, all in good national standing; 12 sedentary men served as control subjects. The relationship between $\mathrm{VO}_{2}$ and work-output appeared to be linear in most of the subjects, but a plateau phenomenon was observed in two sprinters and two endurance runners. An upwards curvilinear increase in $\mathrm{VO}_{2}$ was noticed during the last two minutes of exercise in four endurance runners, but not in any of the sprinters. The four endurance runners with this unexpected increase in $\mathrm{VO}_{2}$ had a significantly higher $(p<.01)$ "peak $\mathrm{VO}_{2}$ " (mean $=75.3 \mathrm{ml}^{\prime} \mathrm{kg}^{-1} \cdot \mathrm{min}^{-1}$ ) than the rest of the endurance runners (mean $=55.1)$, and a significantly higher $(p<.001)$ peak $\mathrm{VO}_{2}$ than the sprinters $($ mean $=46.0)$.

It is concluded that the plateau phenomenon appears in runners during graded cycle ergometry, though rather seldom. It is less clear if the endurance runners showing the upwards curvilinear increase in $\mathrm{VO}_{2}$ possess a better aerobic performance capacity towards the end of progressive exercise. Nevertheless, the linear relationship between $\mathrm{VO}_{2}$ and work load does not appear to be the only one observed in runners during graded exercise.
\end{abstract}

Key words: Bicycle exercise, oxygen uptake, training.

\section{INTRODUCTION}

It has been proposed that the "levelling-off" sometimes shown in oxygen consumption $\left(\mathrm{VO}_{2}\right)$ during progressive cycle ergometer exercise is merely a consequence of an "apparent peaking-over" due to reduced work-output at the end of exercise (Katch and Katch, 1973), and also that in general the plateau phenomenon does not appear when several work loads are combined in a single continuous task (Taylor, Wang et al, 1963). Furthermore, cardiac output and $\dot{\mathrm{V}}_{2}$ have been observed to maintain a linear relationship during graded cycle ergometry (Faulkner, Heigenhauser et al, 1977). Individual differences in the ability to sustain stroke volume at maximal heart rates have been noticed, and age and training have been suggested as pertinent factors (Ouellet, Poh et al, 1969). Differences in the anatomy and function of the left ventricle of the heart at rest have also been observed between sprinters and endurance runners (Ikäheimo et al, 1979). 
The purpose of our study was to find out if the linear relationship between $\dot{\mathrm{VO}}_{2}$ and work-output is the only one existing in sprinters and endurance runners throughout graded cycle ergometry, and to investigate whether the two groups of athletes differ from each other with respect to the $\mathrm{VO}_{2}$ response when the exhaustive level is approached in this type of progressive exercise.

\section{METHODS}

Subjects. Twenty-one competing men athletes (9 sprinters and 12 endurance runners) were studied. Twelve sedentary men served as control subjects. The physical characteristics of the subjects are presented in Table 1.

\section{TABLE I}

Physical characteristics of the subjects*

\begin{tabular}{lrrr} 
& \multicolumn{3}{c}{ Athletes } \\
& $\begin{array}{c}\text { Sprinters } \\
(n=9)\end{array}$ & $\begin{array}{c}\text { Endurance } \\
\text { Runners } \\
(n=12)\end{array}$ & $\begin{array}{c}\text { Controls } \\
(n=12)\end{array}$ \\
& $23.2 \pm 3.6$ & $27.35 \pm 3.7$ & $28.5 \pm 2.3$ \\
Age $(y r)$ & $8.4 \pm 2.4$ & $8.5 \pm 3.4$ & - \\
Training years & $180.7 \pm 5.6$ & $175.6 \pm 5.3$ & $179.3 \pm 4.6$ \\
Height $(\mathrm{cm})$ & $72.5 \pm 5.9$ & $66.0 \pm 6.6$ & $74.8 \pm 5.1$ \\
Weight $(\mathrm{kg})$ & & &
\end{tabular}

*Values are means $\pm S D$

The 12 endurance runners comprised 5 marathon runners, 4 intermediate distance runners, and 3 athletes who were both skiers and cross-country runners. All 12 athletes were in good national standing, 2 runners being national championship medallists. The training programme involved typical endurance training, including one weekly interval-training period. These men ran 105 to $210 \mathrm{~km}$ (mean $162 \mathrm{~km}$ ) weekly. The study was made in the spring at the end of the endurance training period.

All the sprinters were also in good national standing; three were medallists in national championship competitions. The weekly training programme consisted of 2 or 3 (mean 2.2) sessions of power training with light weights, 1 to 3 sessions of speed training with short (less than $60 \mathrm{~m}$ ) running spurts and 1 to 4 (mean 2.4) interval-training sessions with repeated running of 100 to $400 \mathrm{~m}$.

Equipment. The cycle ergometer was electrically braked (Godart-Statham). The calibration of the ergometer was checked every month. The subjects breathed through an open low resistance mouthpiece, with the nose closed by a clamp. We used two recording systems: (1) $\dot{\mathrm{V}} \mathrm{O}_{2}$, expired carbon dioxide $\left(\dot{V} \mathrm{CO}_{2}\right)$, respiratory quotient $(R)$, tidal $\left(\dot{V}_{T}\right)$ and minute $\left(\dot{V}_{E}\right)$ ventilation, respiratory rate (f), heart rate (HR) and work were measured every minute throughout the exercise with a computer-based system (Pulmorex, Fenyves et Gut). (2) The mean differences of concentrations of $\mathrm{O}_{2}$ $\left(\triangle \mathrm{FO}_{2}\right)$ and $\mathrm{CO}_{2}\left(\triangle \mathrm{FCO}_{2}\right)$ between expired air and standard gas, $V_{T}, \dot{V}_{E}, f$, and $H R$ were recorded by a multichannel recorder with a recorder speed of $50 \mathrm{~mm} / \mathrm{s}$. A paramagnetic analyser (Rapox, Godart) was used to determine $\mathrm{VO}_{2}$, and an infrared analyser (Capnograp, Godart) to obtain values for expired $\mathrm{CO}_{2}$. The instruments were checked and calibrated by comparison with samples of known gases.

Test protocol. The tests were performed according to a progressive protocol: the starting work load was $30 \mathrm{~W}$ and every minute the load was increased by $15 \mathrm{~W}$. The subjects were encouraged verbally to continue to subjective exhaustion. The required pedalling rate was $60 \mathrm{rpm}(1 \mathrm{~Hz})$. Only full minutes were accepted in the results.

The criteria for oxygen uptake $\left(\mathrm{VO}_{2}\right)$ responses were based upon the attainment of a plateau in $\mathrm{VO}_{2}$ when at least the last three $\mathrm{VO}_{2}$ values at the plateau level agreed to within 5\% (Davies, 1969; Niemelä et al, 1980). An increase in $\mathrm{VO}_{2}$ more than this, but within three standard deviations ( $3 \mathrm{SD}$ ) of the mean increase in $\mathrm{VO}_{2}$ observed during one work load at the submaximal level in our laboratory (Niemelä et al, 1980), was considered to be linear, whereas an increase in $\mathrm{VO}_{2}$ above 3 SD was considered as being upwards curvilinear ("unexpectedly" high"). The highest $\mathrm{VO}_{2}$ achieved for each subject was termed "peak $\mathrm{VO}_{2}$ ". Standard t-tests were used for comparisons between different $\dot{\mathrm{VO}}_{2}$ responses. Significance was established at the 0.05 level of confidence.

\section{RESULTS}

The average maximal values obtained during maximal exercise in the sprinters, the endurance runners and the controls are presented in Table II. Local leg discomfort did not appear to prevent the attainment of subjective exhaustion in our subjects.

Table III shows the three types of $\dot{\mathrm{VO}}_{2}$ response at the maximal level of exercise in our subjects. Among the athletes, a plateau in $\dot{\mathrm{VO}}_{2}$ was observed in two sprinters and two endurance runners, whereas an upwards curvilinear increase was seen in four endurance runners, but not in any of the sprinters. Of the controls, one subject showed the plateau, and one subject the "unexpectedly high increase" in $\mathrm{VO}_{2}$. Therefore, later comparisons were made only among the athletes. Altogether, in twenty-three of our 33 subjects, $\mathrm{VO}_{2}$ continued to rise as work load was increased (linear increase).

As can be seen in Fig. 1, $\mathrm{VO}_{2}, \mathrm{VCO}_{2}$ and $\mathrm{V}_{E}$ increased almost linearly in all three categories of response before the last two minutes of exercise, when in the unexpectedly high $\mathrm{VO}_{2}$ response group, oxygen uptake, expired carbon dioxide and minute ventilation became clearly 
TABLE II

Maximal ergometric values of oxygen uptake $\left(\dot{\mathrm{V}}_{2}, \mathrm{STPD}\right)$, minute ventilation $\left(\dot{\mathrm{V}}_{\mathrm{E}}, \mathrm{BTPS}\right)$, heart rate (HR), respiratory exchange ratio $(R)$ and work load for the sprinters, the endurance runners and the controls*

\begin{tabular}{|c|c|c|c|c|c|c|}
\hline & & & & & & \\
\hline & & & & & & Endurance \\
\hline & $\begin{array}{c}\text { Sprinters } \\
(n=9)\end{array}$ & $\begin{array}{c}\text { Endurance } \\
\text { Runners } \\
\text { (n=12) }\end{array}$ & $\begin{array}{l}\text { P-value } \\
\text { between } \\
\text { Athletes }\end{array}$ & $\begin{array}{l}\text { Controls } \\
(n=12)\end{array}$ & $\begin{array}{c}\text { Sprinters } \\
\text { vs } \\
\text { Controls }\end{array}$ & $\begin{array}{c}\text { Runners } \\
\text { vs } \\
\text { Controls }\end{array}$ \\
\hline$\dot{\mathrm{V}} \mathrm{O}_{2}\left(\mathrm{~L} \cdot \mathrm{min}^{-1}\right)$ & $3.35 \pm 0.65$ & $4.14 \pm 0.91 .1$ & $<.05$ & $3.05 \pm 0.60$ & ns & $<.01$ \\
\hline$\dot{\mathrm{V}}_{2}\left(\mathrm{ml} . \mathrm{kg}^{-1} \cdot \mathrm{min}^{-1}\right)$ & $46.0 \pm 7.6$ & $62.6 \pm 11.9$ & $<.01$ & $40.8 \pm 7.4$ & ns & $<.001$ \\
\hline$\dot{\mathrm{V}}_{\mathrm{E}}\left(\right.$ L.min..$\left.^{-1}\right)$ & $114.3 \pm 18.9$ & $128.2 \pm 25.8$ & ns & $90.5 \pm 18.3$ & $<.05$ & $<.001$ \\
\hline HR (beats/min.) & $193 \pm 9$ & $190 \pm 9$ & ns & $192 \pm 9$ & ns & ns \\
\hline $\mathbf{R}$ & $1.21 \pm 0.05$ & $1.23 \pm 0.07$ & ns & $1.19 \pm 0.09$ & ns & ns \\
\hline Work load (W) & $332 \pm 46$ & $358 \pm 34$ & ns & $262 \pm 33$ & $<.01$ & $<.001$ \\
\hline
\end{tabular}

*Values are means $\pm S D \quad n s=$ not significant

\section{TABLE III}

Three types of $\dot{\mathrm{VO}}_{2}$ response at the maximal level of exercise in sprinters, endurance runners and controls

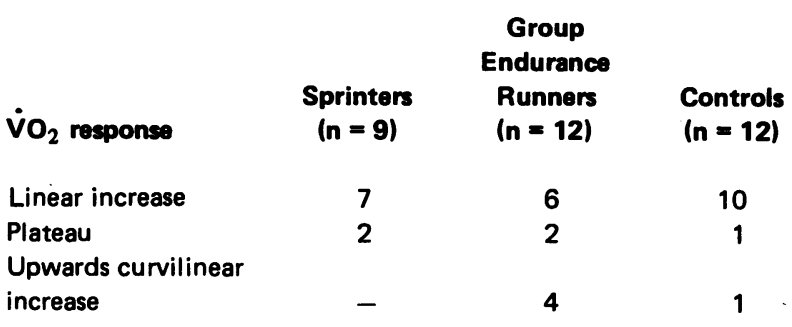

curvilinear upwards, and neither $\dot{\mathrm{V}}_{\mathrm{E}}$ nor $\dot{\mathrm{V}} \mathrm{CO}_{2}$ seemed to increase out of proportion to $\mathrm{VO}_{2}$, whereas heart rate continued to rise linearly. In the other two $\dot{\mathrm{VO}}_{2}$ response groups, hyperventilation was noticed with respect to oxygen uptake at the end of exercise. The curvilinear increase in $\dot{V}_{E}$ occurred by an increase in respiration rate rather than by an increase in $\mathrm{V}_{\mathrm{T}}$.
The average increases in $\dot{\mathrm{VO}}_{2}, \dot{\mathrm{V}} \mathrm{CO}_{2}$ and $\dot{\mathrm{V}}_{\mathrm{E}}$ shown in Fig. 1 were not found to be significantly different between any of the three $\dot{\mathrm{VO}}_{2}$ response groups until during the last two minutes of exercise. Between the unexpectedly high $\dot{\mathrm{V}}_{2}$ response group and the plateau group, and between the unexpectedly high group and the linear $\dot{\mathrm{V}}_{2}$ response group, significant differences were noted for the increase in $\mathrm{VO}_{2}$ during the last two minutes, for the increase in $\mathrm{VCO}_{2}$ during the last minute, and for the increase in $\dot{V}_{E}$ during the penultimate minute of exercise (Table IV). Between the linear response group and the plateau group the only observed significant difference $(p<.05)$ was in the higher increase in $\mathrm{VO}_{2}$ during the penultimate minute in the linear response group.

The decrease in $\triangle \mathrm{FCO}_{2}$ during the last minutes of exercise was similar in all three $\mathrm{VO}_{2}$ response groups (Fig. 1), and no significant differences were noted between these decreases. $\triangle \mathrm{FO}_{2}$ decreased in parallel in the plateau and the linear groups, whereas in the unexpectedly high $\mathrm{VO}_{2}$ response group $\Delta \mathrm{FO}_{2}$ decreased

\section{TABLE IV}

Significance of differences for the increases in oxygen uptake $\left(\dot{\mathrm{V}} \mathrm{O}_{2}\right)$, expired carbon dioxide $\left(\dot{\mathrm{V}} \mathrm{CO}_{2}\right)$ and minute ventilation $\left(\dot{V}_{E}\right)$ shown in Fig. 1 between the unexpectedly high and the plateau $\dot{V}_{2}$ response, and between the unexpectedly high and the linear $\mathrm{VO}_{2}$ response

\begin{tabular}{|c|c|c|c|c|}
\hline & \multicolumn{2}{|c|}{ P-values during the penultimate minute } & \multicolumn{2}{|c|}{ P-values during the last minute } \\
\hline Variables & $\begin{array}{c}\text { Unexpectedly high } \\
\text { vs } \\
\text { Plateau response }\end{array}$ & $\begin{array}{l}\text { Unexpectedly high } \\
\text { vs } \\
\text { Linear response }\end{array}$ & $\begin{array}{c}\text { Unexpectedly high } \\
\text { vs } \\
\text { Plateau response }\end{array}$ & $\begin{array}{c}\text { Unexpectedly high } \\
\text { vs } \\
\text { Linear response }\end{array}$ \\
\hline $\begin{array}{l}\dot{\mathrm{VO}}_{2} \\
\dot{\mathrm{V}} \mathrm{CO}_{2} \\
\dot{\mathrm{V}}_{\mathrm{E}}\end{array}$ & $\begin{array}{l}<.05 \\
\text { ns } \\
<.05\end{array}$ & $\begin{array}{l}<.05 \\
\text { ns } \\
<.01\end{array}$ & $\begin{array}{l}<.05 \\
<.01 \\
\mathrm{~ns}\end{array}$ & $\begin{array}{l}<.01 \\
<.001 \\
\text { ns }\end{array}$ \\
\hline
\end{tabular}


during the last minute significantly less $(p<.01)$ than in the other two $\dot{\mathrm{VO}}_{2}$ response groups. During the last two minutes $\triangle \mathrm{FO}_{2}$ decreased significantly less $(p<.05)$ in the unexpectedly high $\dot{\mathrm{VO}}_{2}$ response group than in the plateau group.

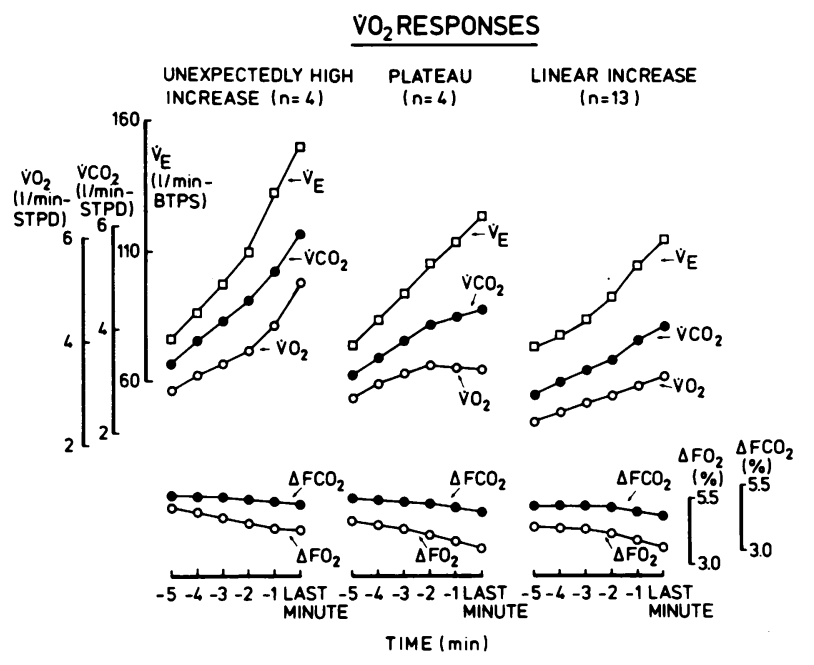

Fig. 1. Average increases in oxygen uptake $\left(\dot{\mathrm{V}} \mathrm{O}_{2}\right)$, expired carbon dioxide $\left(\dot{V} \mathrm{CO}_{2}\right)$ and minute ventilation $\left(\dot{V}_{E}\right)$, and average decreases in excreted oxygen $\left(\triangle F O_{2}\right)$ and carbon dioxide $\left(\triangle \mathrm{FCO}_{2}\right)$ fractions. Differences during the last minutes of progressive bicycle exercise in three $\dot{V}_{2}$ response groups within the runners.
The four endurance runners with the unexpectedly high $\mathrm{VO}_{2}$ response had a higher average "peak $\mathrm{VO}_{2}$ " (both in L.min. ${ }^{-1}$ and $\mathrm{ml} \cdot \mathrm{kg}^{-1} \cdot \mathrm{min}^{-1}$ ) and $\dot{\mathrm{V}} \mathrm{CO}_{2}$, and a lower $R$ than the athletes in the other two $\dot{\mathrm{VO}}_{2}$ response groups, whereas a significantly higher $(p<.01)$ maximal $\dot{V}_{E}$ and cycling time were noted in these four subjects only in comparison with the subjects in the linear $\dot{\mathrm{VO}}_{2}$ response group. These four endurance runners also had a significantly higher $(p<.01)$ average peak $\mathrm{VO}_{2}\left(75.3 \mathrm{ml} . \mathrm{kg}^{-1}\right.$. $\left.\mathrm{min}^{-1}\right)$ than the rest of the endurance runners (55.1). Between the athletes showing the plateau and the linear $\dot{\mathrm{VO}}_{2}$ response, no significant differences for these values were observed (Table V).

\section{DISCUSSION}

Intensive endurance training is usually started at a somewhat greater age than speed training, and consequently our endurance runners were slightly older than the sprinters. Short-distance runners are usually tall and powerfully built, and in our subjects the sprinters were taller and heavier than the endurance runners. However, as the two groups did not differ with regard to the number of years of training, and as both groups consisted of athletes in good national standing, it seems justifiable to compare these two groups of athletes in regard to the exercise capacity.

Progressive exercise tests, as described by Balke and Ware (1959) for example, have been noticed to result in similar $\mathrm{VO}_{2}$ max values when compared with discontinuous protocols (Maksud and Coutts, 1971). Though on average a $5-8 \%$ lower $\mathrm{VO}_{2}$ max is obtained on a cycle

\section{TABLE V}

Maximal values of oxygen uptake $\left(\dot{\mathrm{V}} \mathrm{O}_{2}, \mathrm{STPD}\right)$, expired carbon dioxide $\left(\dot{\mathrm{V}} \mathrm{CO}_{2}, \mathrm{STPD}\right)$, minute ventilation $\left(\dot{\mathrm{V}}_{\mathrm{E}}, \mathrm{BTPS}\right)$, respiratory exchange ratio $(R)$ and cycling time during maximal exercise in the three $\mathrm{VO}_{2}$ response groups within the athletes*

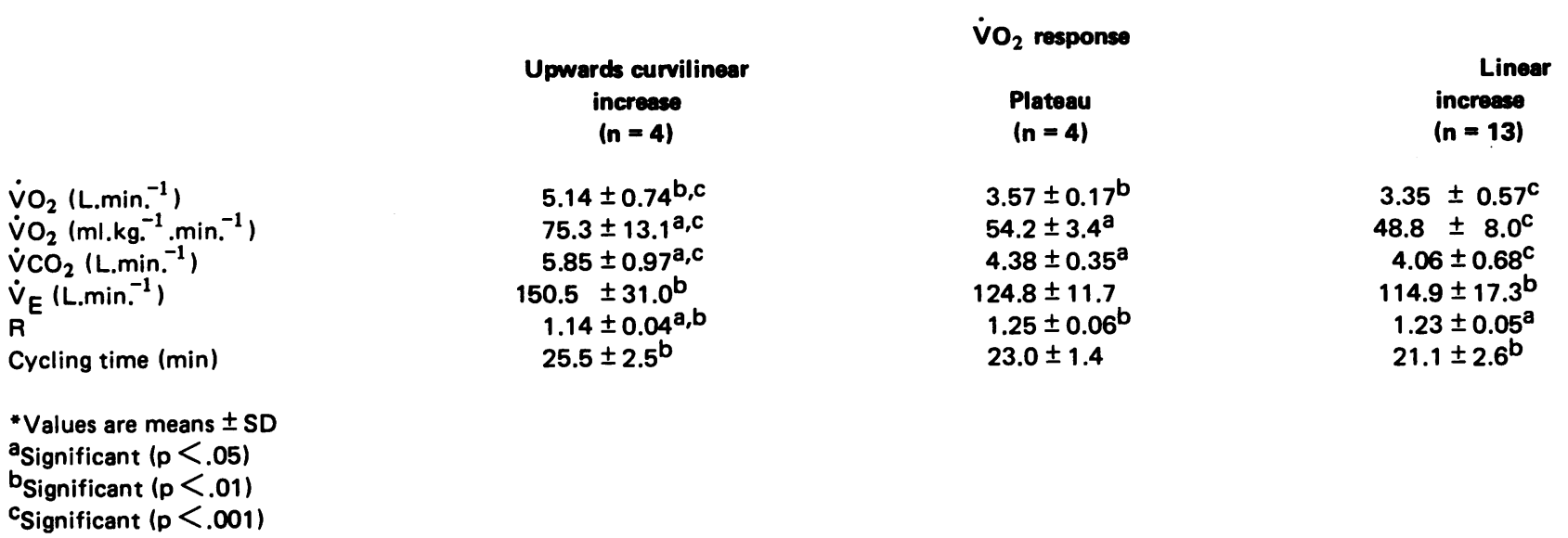

\footnotetext{
$\dot{V O}_{2}\left(\right.$ L. min. $\left.^{-1}\right)$

$\dot{\mathrm{V}} \mathrm{O}_{2}\left(\mathrm{ml} . \mathrm{kg}^{-1} \cdot \mathrm{min}^{-1}\right)$

$\dot{\mathrm{COO}}_{2}$ (L.min. $^{-1}$ )

$\dot{\mathrm{V}}_{\mathrm{E}}\left(\right.$ L.min. $\left.{ }^{-1}\right)$

*Values are means \pm SD

CSignificant $(p<.001$ )
} 
ergometer than on a treadmill ( $\AA$ strand and Rodahl, 1977; Hermansen and Saltin, 1969; Kamon and Pandolf, 1972), this has not been considered to be of practical importance (Åstrand, 1976). As expected, our endurance runners achieved significantly higher "peak" oxygen uptake than the sprinters, which was, however, lower than described in elite distance runners on a treadmill (Pollock, 1977), establishing the well-known fact that the cycle test is not the best test for runners if the purpose is to measure $\mathrm{VO}_{2}$ max. However, when the purpose is to evaluate the relationship between $\dot{\mathrm{VO}}_{2}$ and work-output, the cycle ergometer has the advantage of enabling an accurate determination of work load when compared with the treadmill.

It seems reasonable to assume that in general our runners achieved their maximum performance in the cycle test, though we had the opportunity to test each athlete only once: well-trained athletes are used to exhausting themselves completely, and leg discomfort did not appear to prevent the attainment of subjective exhaustion in our athletes. Furthermore, if the difference in $\dot{\mathrm{V}}_{2}$ max observed during cycling and running is taken into account, the peak oxygen uptake values observed in our endurance runners were in general satisfyingly high. In addition, lower " $\mathrm{VO}_{2} \max$ " values than those observed in our endurance runners have been described in well-trained endurance runners during cycling (Yamaji and Miyashita, 1978).

As expected, oxygen consumption increased almost linearly for a given work load in most of our sprinters and endurance runners, but in some of them the plateau phenomenon was noticed. This "levelling-off" did not appear to be explained by an "apparent peaking-over" in $\mathrm{VO}_{2}$ due to reduced work-output (Katch and Katch, 1973), because of the electrically braked cycle we used. The sprinters, with presumably more powerful leg muscles, did not appear to be superior to the endurance runners with respect to the attainment of the plateau in $\dot{\mathrm{V}}_{2}$. Hence, the plateau phenomenon obviously does appear in runners during graded cycle exercise, though rather seldom.

An upwards curvilinear increase in $\dot{\mathrm{VO}}_{2}$ was noticed at the exhaustive level of exercise in some of our endurance runners, who also achieved a rather high oxygen uptake when measured on a cycle ergometer, but not in any of the sprinters. In these endurance runners, neither $\dot{\mathrm{V}} \mathrm{CO}_{2}$ nor $\dot{\mathrm{V}}_{\mathrm{E}}$ were noticed to increase out of proportion to $\mathrm{VO}_{2}$, whereas the common relationship $\uparrow \dot{V}_{E}>\uparrow \dot{V} \mathrm{CO}_{2}>\uparrow \dot{V} O_{2}$ (Wasserman, Whipp et al, 1977), could be noticed in the subjects showing the plateau or the linear increase in $\mathrm{VO}_{2}$. The significantly lower respiratory quotient noticed in the athletes with the unexpected increase in $\mathrm{V}_{2}$ appeared to be explained by a higher $\mathrm{O}_{2}$ extraction, whereas the expired $\mathrm{CO}_{2}$ content was approximately at an equal level in all three
$\dot{\mathrm{V}} \mathrm{O}_{2}$ response groups.

Circulatory factors are generally accepted to limit the maximal aerobic exercise capacity in healthy subjects (Davies, 1968; Wyndham, Strydom et al, 1959). Thus, any increase in $\mathrm{O}_{2}$ uptake beyond the circulatory limit would be a consequence of the $\mathrm{O}_{2}$ cost of breathing at high levels of ventilation, that is, any increase in $\mathrm{O}_{2}$ extraction achieved by a further increase in ventilation would be utilised solely by the respiratory muscles. Thus, the $\mathrm{O}_{2}$ cost of breathing could explain the upwards curvilinear increase in $\mathrm{VO}_{2}$ and the higher $\mathrm{O}_{2}$ extraction noticed in some of our subjects. The fact that any of the three $\mathrm{VO}_{2}$ responses could be noticed at equally high levels of ventilation, and that this increase was also noticed in one sedentary control subject at a rather low level of ventilation, does not clearly support this hypothesis. Furthermore, the $\mathrm{O}_{2}$ cost of breathing has been proposed to account for the increase in $\mathrm{VO}_{2}$ after the circulatory limit has been exceeded (Ouellet, Poh et al, 1969), but in our subjects with this upwards curvilinear increase in $\mathrm{VO}_{2}$ we did not observe any tendency to a "levelling-off" in heart rate at the end of exercise, indicating that the circulatory limit had not been clearly exceeded.

Thus, the $\mathrm{O}_{2}$ cost of breathing does not appear to be the only explanation for the unexpected increase in $\mathrm{VO}_{2}$. It is also likely that those athletes showing this phenomenon would achieve this at maximum circulation by shunting and effective redistribution of blood to working muscles, which would result in an expanded whole body a-v $\mathrm{O}_{2}$ difference. An increase in body temperature caused by prolonged exercise (Hagberg, Mullin et al, 1978) is hardly sufficient to explain the curvilinear increase in $\mathrm{VO}_{2}$ because the cycling times in the three $\dot{\mathrm{VO}}_{2}$ response groups were not dissimilar or long enough to cause different or full thermogenic effects. The training effect is less likely to explain this unexpected increase in $\mathrm{VO}_{2}$ as it also was noticed in one sedentary control subject.

An ability to sustain stroke volume at maximal levels of work could explain the difference between the linear $\mathrm{VO}_{2}$ response group and the plateau group. It is less clear if the runners showing the upwards curvilinear increase in $\mathrm{V}_{2}$ possess a better aerobic performance capacity towards the end of progressive exercise, or if this phenomenon is only a sequal to secondary changes in the oxygen transport system and, thus, of no practical importance. Measures of cardiac output certainly would help in clarifying the circulatory dynamics of these observations, but they are difficult to perform. It is, perhaps, not possible to make generalisations on the basis of the results of cycle ergometer exercise tests. Nevertheless, the linear relationship between oxygen uptake and work load does not appear to be the only one observed in runners during graded ergometry. 


\section{REFERENCES}

Åstrand, P.-O., 1976 “Quantification of exercise capability and evaluation of physical capacity in man". Progr.Cardiovasc.Dis. 19: 51-67.

Åstrand, P.-O. and Rodahl, K., 1977 "Textbook of work physiology". New York, McGraw-Hill, 2nd ed.

Balke, B. and Ware, R. W., 1959 "An experimental study of 'physical fitness' of Air Force personnel". U.S. Armed Forces Med.J. 10: 675-688.

Davies, C. T. M., 1968 "Limitations to the prediction of maximum oxygen intake from cardiac frequency measurements". J.Appl.Physiol. 24: 700-704.

Faulkner, J. A., Heigenhauser, G. F. and Schork, M. A., 1977 "The cardiac output - oxygen uptake relationship of men during graded bicycle ergometry". Med.Sci.Sports 9: 148-154.

Hagberg, J. M., Mullin, J. P. and Nagle, J. F., 1978 “Oxygen consumption during constant-load exercise”. J.Appl. Physiol. 45: 381-384.

Hermansen, L. and Saltin, B., 1969 "Oxygen uptake during maximal treadmill and bicycle exercise". J.Appl.Physiol. 26: 31-37.

Ikäheimo, M. J., Palatsi, I. J. and Takkunen, J. T., 1979 “Non-invasive evaluation of the athletic heart: sprinters versus endurance runners". Am.J.Cardiol. 44: 24-30.

Kamon, E. and Pandolf, K. B., 1972 "Maximal aerobic power during laddermill climbing, uphill running, and cycling". J.Appl.Physiol. 32: 467-473.

Katch, V. L. and Katch, F. I., 1973 "The relationship between aerobic power and measured work-output on a progressive step increment bicycle ergometer test". Med.Sci.Sports 5: 22-28.

Maksud, M. G. and Coutts, K. D., 1971 “Comparison of a continuous and discontinuous graded treadmill test for maximal oxygen uptake". Med.Sci.Sports 3: 63-65.

Niemelä, K., Palatsi, I., Linnaluoto, M. and Takkunen, J., 1980 “Criteria for maximum oxygen uptake in progressive bicycle tests". Eur.J.Appl.Physiol. 44: 51-59.

Pollock, M. L., 1977 "Submaximal and maximal working capacity of elite distance runners". Ann.N.Y.Acad.Sci. 30: 310-322.

Ouellet, Y., Poh, S. C. and Becklake, M. R., 1969 "Circulatory factors limiting maximal aerobic exercise capacity". J.Appl.Physiol. 27: 874-880.

Taylor, H. L., Wang, Y., Rowell, L. and Blomqvist, G., 1963 "The standardisation and interpretation of submaximal and maximal tests of working capacity". Pediatrics 32: 703-722.

Wasserman, K., Whipp, B. J., Casaburi, R. and Beaver, W. L., 1977 "Carbon dioxide flow and exercise hyperpnea". Am.Rev. Respir.Dis. 115: 225-237.

Wyndham, C. H., Strydom, N. B., Maritz, J. F., Morrison, J. F., Peter, J. and Potgieter, Z. U., 1959 “Maximum oxygen intake and maximum heart rate during strenuous work". J.Appl.Physiol. 14: 927-936.

Yamaji, K. and Miyashita, M., 1978 “Differences in cardio-respiratory responses to exhaustive exercise between athletes and non-athletes". Eur.J.Appl.Physiol. 38: 233-238. 